\title{
Experienced academics' emotions related to assessment
}

\author{
Myyry, Liisa
}

2020-01-02

Myyry , L , Karaharju-Suvanto , T , Vesalainen, M, Virtala , A-M , Raekallio , M , Salminen , O , Vuorensola , K \& Nevgi , A 2020 , ' Experienced academics' emotions related to assessment ' , Assessment \& Evaluation in Higher Education , vol. 45 , no. 1 , pp. 1-13 . https://doi.org/10.1080/026

http://hdl.handle.net/10138/320151

https://doi.org/10.1080/02602938.2019.1601158

unspecified

acceptedVersion

Downloaded from Helda, University of Helsinki institutional repository.

This is an electronic reprint of the original article.

This reprint may differ from the original in pagination and typographic detail.

Please cite the original version. 


\section{Experienced Academics' Emotions Related to Assessment}

Liisa Myyry $^{\mathrm{a} *}$, Terhi Karaharju-Suvanto ${ }^{\mathrm{b}}$, Marjo Vesalainen ${ }^{\mathrm{c}}$, Anna-Maija K Virtala ${ }^{\mathrm{d}}$, Marja R Raekallio $^{\mathrm{e}}$, Outi Salminen ${ }^{\mathrm{f}}$, Katariina Vuorensola ${ }^{\mathrm{g}} \&$ Anne Nevgi $^{\mathrm{h}}$

${ }^{\mathrm{a}}$ Liisa Myyry, Centre for University Teaching and Learning, Faculty of Educational Sciences, University of Helsinki, email: liisa.myyry@ helsinki.fi ORCID: 0000-0001-9337-9547

${ }^{\mathrm{b}}$ Terhi Karaharju-Suvanto, Department of Oral- and Maxillofacial diseases, Faculty of Medicine, University of Helsinki. ORCID: 0000-003-1228-6862

${ }^{\mathrm{c}}$ Marjo Vesalainen, Centre for University Teaching and Learning, Faculty of Educational Sciences, University of Helsinki. ORCID: 0000-0002-0055-0155

${ }^{\mathrm{d}}$ Marja R. Raekallio, Department of Equine and Small Animal Medicine, Faculty of Veterinary Medicine, University of Helsinki. ORCID: 0000-0002-2653-003X

e Outi Salminen, Division of Pharmacology and Pharmacotherapy, Faculty of Pharmacy, University of Helsinki. ORCID: 0000-0003-0427-858X

${ }^{\mathrm{f}}$ Anna-Maija K. Virtala, Department of Veterinary Biosciences, Faculty of Veterinary Medicine, University of Helsinki. ORCID: 0000-0003-2540-9171

${ }^{\text {g} K a t a r i i n a ~ V u o r e n s o l a, ~ D i v i s i o n ~ o f ~ P h a r m a c e u t i c a l ~ C h e m i s t r y ~ a n d ~ T e c h n o l o g y, ~ F a c u l t y ~ o f ~}$ Pharmacy, University of Helsinki.

${ }^{\mathrm{h}}$ Anne Nevgi, Centre for University Teaching and Learning, Faculty of Educational Sciences, University of Helsinki. ORCID: 0000-0003-2301-896X

Correspondence should be addressed to Liisa Myyry, Centre for University Teaching and Learning, A.I.Virtasen aukio 1, Box 55, 00014 University of Helsinki, Finland. Email: liisa.myyry@helsinki.fi 


\begin{abstract}
The aim of this study was to examine the emotions higher education teachers associate with assessment and the factors in their teaching environment that triggered these emotions. As a starting point, Frenzel's model of teacher emotions and Pekrun's Control-Value Theory (CVT) of achievement emotions were used. The sample consisted of 16 experienced and pedagogically advanced teachers who participated in semi-structured interviews. After abductive content analyses, both positive and negative emotions were detected corresponding to Frenzel's and Pekrun's models. The main sources of emotions were validity of assessment, assessment methods, pedagogical development and assessment culture. This preliminary study indicates that assessment evokes both positive and negative emotions, and that validity of assessment is a prominent issue in evoking these emotions. Pedagogical training should deal with emotions and their regulation in assessment to help teachers in higher education to cope with negative emotions.
\end{abstract}

Key words: achievement emotions, higher education, experienced teachers, assessment 


\section{Introduction}

Assessment of student learning is a time-consuming, strenuous and challenging task for academics. It is one of the core responsibilities for academics both as gatekeepers of academic standards and as facilitators of student learning. Working as an assessor, an academic holds the role of a judge and his/her judgement of students' learning outcomes should be fair, impartial and based on transparent criteria. On the other hand, the academic's task as an assessor includes roles as a mentor, tutor, supervisor and teacher, aiming to facilitate students' learning.

Recently, the importance of research on the affective dimension in university teaching has been recognised (Beard, Clegg, and Smith 2007), and the interest in investigating university teachers' emotions in teaching has emerged (e.g. Cowie 2011; Postareff and Lindblom-Ylänne 2011; Hagenauer and Volet 2014; Löfström and Nevgi 2014). However, research focusing on academics' emotions associated with their assessment practice has remained surprisingly scarce. As assessment often includes many emotions crucial to social behavior and decision-making (Damasio 2003), it is important to examine emotions also in academic contexts.

Generally, most researchers in the fields of social psychology, psychology and educational sciences agree that emotions are multi-componential processes consisting of appraisal and subjective experience, and including affective, cognitive, motivational, expressive and peripheral physiological processes (Sutton and Wheatley 2003; Pekrun 2006). Appraisal is an evaluation of the significance of the environment to well-being (Smith \& Lazarus 1993; Moors, Elisworth, Scherer and Frijda 2013). It triggers and differentiates emotional episodes, i.e. determines the intensity and quality of action tendencies, psychological responses, behavior and feelings (Moors et al. 2013). Feeling, among others, is only one component in the emotional construct, which allows individuals to express the emotional experiences to others (Scherer 2009). 


\section{Emotions related to teaching}

Frenzel and her colleagues (Frenzel 2014; Frenzel et al. 2016) have designed a model of teacher emotions and a scale to test those emotions in school context (Teacher Emotions Scales, hereafter TES). The model is based on appraisal theory (e.g. Moors, Elishworth, Scherer \& Frijda 2013), stating that emotions are primarily caused by individuals' subjective cognitive judgments about significant situations and events rather than by the situations and events themselves (Frenzel 2014). The TES measures three emotions considered most relevant in the context of teaching: enjoyment, anger and anxiety. The TES assumes that emotions are states more than traits; i.e. emotions are seen as temporary experiences, instead of more stable and general feelings (Frenzel et al. 2016). Enjoyment is defined as experiencing well-being and pleasure resulting from an upcoming (anticipatory joy) or a past (outcome related joy) event or from being engaged in an enjoyable activity. For enjoyment and pride - an emotion closely linked to enjoyment but not included in the TES per se - the main source seems to be students' success (Frenzel 2014). Anger can be the most salient negative emotion in teaching (e.g Sutton \& Wheatley 2003), and it is typically evoked when we can blame others for undesirable events (Smith \& Lazarus 1993), for instance pupils for misbehaving, or ourselves (feeling unsatisfied to one's own behavior) (Frenzel 2014). Because experiencing anger in teaching contexts is socially undesirable, it may be reported more seldom than it is felt (Frenzel 2014). Threat and a perception that one is not capable to cope with it, evokes anxiety (Smith and Lazarus 1993); for example, poor preparation for teaching or problems with discipline in the classroom can trigger anxiety, and it seems to be more common among young teachers (Frenzel 2014).

\section{Emotions Related to University Teaching}

Plenty of research exists about emotions in higher educational settings (Pekrun 2006; Pekrun, Elliot and Maier 2009; Pekrun, Goetz, Frenzel, Barchfeld and Perry 2011; Peterson, Brown, and Jun 2015), generally under the topic of achievement emotions. Achievement emotions are defined as 
emotions that are directly tied to achievement activities or achievement outcomes (Pekrun et al. 2017). Achievement activities refer to tests, assignments and performances both in examination conditions and as take-home tasks, whereas achievement outcomes refer to for instance grades and scores. Not all emotions experienced in learning contexts are achievement emotions, but considering the aims of learning and education, they are crucial.

Currently the most commonly used framework to study achievement emotions is Pekrun's (2006) Control-Value Theory (hereafter CVT) (see also Pekrun and Perry 2014). Empirical evidence indicates that achievement emotions have three dimensions: 1) valence (positive/pleasant vs. negative/unpleasant); 2) activation (activating vs. deactivating); and 3) object focus (activity vs. outcome). Positive achievement emotions include emotions such as joy, hope, pride, gratitude, relief, and negative emotions include e.g. anger and frustration (Pekrun et al. 2017). Typically, positive emotions are activating, apart from those felt after accomplishment (e.g. relaxation and relief). (Peterson, Brown, and Jun 2015.) In contrast, negative emotions seem to be equally split into those that increase effort to improve (anger, frustration, anxiety and shame), and those that decrease effort (boredom, sadness, disappointment, hopelessness) (Pekrun et al. 2017). Outcome emotions, pertaining to the outcomes of achievement activities, can be prospective and anticipatory (e.g. hope for success, anxiety of failure) or retrospective (e.g. pride or shame experiences after feedback of achievement) (Pekrun 2006).

Albeit most of the studies about achievement emotions have examined students, Pekrun et al. (2007) emphasize that the same emotions are also relevant to other actors in educational contexts, such as teachers. There is plenty of research concerning for instance university teachers' academic development and teacher identity (see eg. van Lankveld et al. 2016), and the role of emotions in identity development (e.g. Day and Leitch 2001; Zembylas 2003), but studies in teaching contexts, and on assessment particularly, are rare. 
With regard to academics' emotions related to assessment of student learning, those associated with student plagiarism have been addressed (Collins and Amodeo 2005; Sutherland-Smith 2005; Nevgi and Löfström 2014; Vehviläinen, Löfström, and Nevgi 2017). According to Nevgi and Löfström (2014), one of the most stressful of academics' roles is to be a gatekeeper of academic standards. Vehviläinen, Löfström, and Nevgi (2018) observed that teachers' emotional reactions to student plagiarism included annoyance, disappointment, anger, disbelief, shame, anxiety causing a rupture in the personal pedagogical relationship with a student. Teachers seem to feel concern when they have to fail students and block their studies (Ilott and Murphy 1997).

In Finland, university teachers' emotions have been studied for example in relation to their focus of teaching (learning vs. content) and confidence as teachers (Postareff and Lindblom-Ylänne 2011); in how they illustrate themselves as teachers in drawings (Löfström and Nevgi 2014), and while receiving negative student feedback (Lutovac et al. 2017). Both positive (such as enthusiasm, enjoyment, curiosity) and negative (such as reluctance, anxiety and discontent) emotions emerged in all studies. Most of the respondents were pedagogically advanced and trained teachers. Focusing on student learning and professional development was linked to positive emotions whereas focusing on content and negative consequences was related to neutral or negative emotions (Postareff and Lindblom-Ylänne 2011; Lutovac et al. 2017). Postareff and Lindblom-Ylänne (2011) observed also empathy and respect towards students, both emotions that are found to be common among school teachers (Sutton and Wheatley 2003). This kind of compassion can be defined as concern for others in need (Damasio 2003)

\section{Emotions Related to Academics' Assessment Practice}

Assessment plays a critical role in higher education since university students' learning is largely guided by the ways they are assessed (Scouller and Prosser 1994; Scouller 1998; Gibbs and Simpson 2004). There is some research about burnout, workload and emotional exhaustion in the context of teaching (see eg. Lackritz 2004; Ogbonna and Harris 2004; Watts and Robertson 2011; 
Kyvik 2013; Boyd 2014; Melin, Astvik, and Bernhard-Oettel 2014), although only a few studies looked at the relationship between workload and teaching in detail. Lackritz (2004) observed that of workload issues, teaching load, time used for grading and reading papers and assignments, and time spent in office hours talking with students, related to emotional exhaustion.

It seems that as for students, positive emotions buffer maladaptive practices for teachers (Postareff and Lindblom-Ylänne 2011) and can predict positive psychological processes (Lutovac et al. 2017). Nevertheless, we know surprisingly little about how university teachers experience assessing students' learning and how emotions relate to these experiences.

\section{The Aim of the Present Study}

As assessment often includes several emotions, and is crucial for students' learning, the aim of the current study was to investigate teachers' emotions related to assessment in higher education. Because the Control Value Theory covers more emotions than the Teacher Emotions Scale, and the models are overlapping, both models are used as a starting point of this study.

Consequently, in the present research we ask,

1. What kind of emotions do experienced university teachers associate to their work as an assessor?

2. What is the trigger of the emotion and to which context is the emotion associated?

\section{Methods}

\section{Collection of the Data, Respondents and Procedure}

The data were collected by semi-structured interviews of 16 academics ( 8 males and 8 females). Interviewees were found from among those who participated in a survey dealing with assessment practices, and volunteered to be interviewed. All respondents were experienced and pedagogically 
skillful university teachers who had received a nomination as being expert in teaching (members of Teachers’ Academy https://www.helsinki.fi/en/university/teachers-academy).

The interviews included questions about defining assessment and feedback, assessment methods used and procedures as well as justice issues related to assessment (its reliability and validity). One set of questions focused on the interviewee's emotions related to assessment practices, but emotions were analyzed throughout the entire interview as we noticed them being associated with several assessment-related topics.

The interviews were conducted by the members of the research group; each member interviewed two participants. The interviews, which lasted from 30 to 80 minutes, were recorded and transcribed verbatim. The interviews were conducted in respondents' office or in some other silent and convenient place.

\section{Analyses}

The data were analyzed using abductive content analysis (Timmermans and Tavory 2012) and all the members of the research group participated in the analyses. First, each member read thoroughly her two interviews marking the text segments that could be interpreted as expressing emotions. Following Postareff and Lindblom-Ylänne (2011), all descriptions identified as involving an emotion were considered as units of analysis. The research group discussed their findings until they reached mutual understanding concerning what kind of text segments expressed emotion, negative or positive, related to respondents' work as assessors. Secondly, all members of the research group separately coded their own interviews and marked each text segment that included negative and positive emotions pertained to assessment practices.

After the first round, the research group compared the preliminary identified categories of negative and positive emotions with the categories of the TES (Frenzel 2014; Frenzel et al. 2016) and achievement emotions defined by Pekrun (2006; Pekrun et al. 2007), but not limited to them. At the 
second round, each interviewer re-coded her interviews by applying categories of emotions (Pekrun 2006; Pekrun et al. 2007; Frenzel 2014). Furthermore, each interviewer coded two other interviews that were randomly shared within the research group. At the third round, the research group first discussed together their findings and interpretations of the identified categories of emotions, and they were classified as achievement and professional emotions (see Table 1 for expressed emotions and their references). Thereafter, the research group worked in pairs comparing the text segments that expressed emotions, and the data was re-checked as to consistency of the classifications. An outside coder coded 50 randomly chosen emotion episodes with an interrater agreement of $86 \%$ for emotions. Finally, the sources of the emotions, i.e. events that caused the emotions (hereafter called triggers) were identified utilizing content analysis to find events or situations connected to emotions.

For the quantification of the data, all members of the research group counted the number of diverse emotions in their own interviews. The descriptive statistics were calculated in order to find out how the emotions varied in the data. For statistical analyses SPSS 24.0 was used (IBM SPSS Statistical Package version 21, USA). For proportions $95 \%$ confidence intervals were calculated with the EpiTools calculators (Sergeant 2018) using Jeffrey’s method (Brown, Cai, and DasGupta 2001).

\section{Results}

\section{Assessment-Related Emotions among Experienced University Teachers}

Altogether 284 text segments with expressed emotions related to assessment were identified: 102 expressions of positive emotions and 182 expressions of negative emotions (see Table 1). Of the emotions in Pekrun's (2006) CVT model, gratitude, sadness, hopelessness and anger were not detected, but compassion (Sutton and Wheatly 2003; Postareff and Lindblom-Ylänne 2011) was identified.

[Table 1 about here] 


\section{Positive Emotions}

Altogether five positive emotions were identified from the interviews: joy, compassion, relief, hope and pride. Most of the respondents (10/16) expressed feelings of joy when they talked about assessment, especially in response to various novel summative assessment methods such as group, oral or home examinations and learning diaries (quotations in italics).

For me, oral examinations have been of great fun.

Teachers thought that these methods supported learning more than for example a traditional examination and they experienced joy when they saw that students participated in these new ways of assessment enthusiastically and actively. In the context of summative assessment, joy was experienced especially when students succeeded, and teachers noticed a successful learning process. Of course, it makes me happy if someone has done well.

To follow the learning process is one of the finest parts in my work [...] I value hugely to be able to see when someone learns compared to the starting level, compared to the background [...] I get emotional when following the learning process.

Some teachers thought that giving formative feedback was more enjoyable than grading. In the context of formative assessment teachers experienced joy in relation to students' response to feedback. Moreover, joy was triggered by pedagogical development in relation to assessment. The more familiar one was with the aspects of assessment, the more meaningful assessment was. Colleagues' and students' support in developing assessment was a source of joy. Teachers experienced joy when their colleagues encouraged them to experiment with new ways to assess and when they had noticed changes in the assessment culture. 
And sometimes it is just the most fun when you only can give formative feedback...During the course, formative assessment is much more fun than the summative.

It is really nice to assess together with a colleague, it kind of helps to see the light.

Also fairness of assessment induced joy:

I can say that I wait for the outcomes [of the examination] almost as eagerly as the students, just how well they have done and what was the mean grade [...] and if the grades are good, Ifeel slight happiness about it.

From the 16 respondents, nine showed compassion while talking about assessment. Feelings of compassion were triggered by assessment methods (e.g. offering alternative assessment methods to help students pass the course), workload of students (e.g. relieving students' workload by formative assessment), validity of assessment (e.g. taking into account different life situations in assessment), learning process (e.g. feeling responsible for students' learning), and assessment culture (e.g. trying to reach mutual understanding with students about assessment).

I think that feedback should be given all the time so that they could change their learning if they see that they are studying somewhat improperly. It is important for me that feedback is given in an unnoticed way that it does not stress the students and make them feel that it is an assessment situation where you have to learn but the feedback comes within teaching all the time.

...but how we measure the students when the assessment type can influence results, or a flu or badly slept night or hangover, or whatever in the present life situation can influence the performance of the student. Is it fair that just one moment...

Teachers felt relief most often when they could work together with their colleagues when assessing student assignments. They felt that this enhances constructive alignment in the teaching process and ensures justice in the assessment process: 
...we read the answers in pairs - one reads first thoroughly but the other reads also so that we are able to discuss together and somehow it feels really relieving.

Many teachers considered that they are improving as assessors, and there were several expressions of hope in the interviews. Teachers also were hopeful about the ongoing development of assessment methods in the teaching community, and expressed hopefulness that these improvements would save their own time and effort:

...in our department we are finally clarifying the grading system and making the assessment criteria for master's thesis clearer.

In addition, teachers were hopeful that pedagogical training or organizational changes would increase general willingness to develop teaching and assessment.

Teachers felt pride about their personal way of teaching and assessing - feeling that they were able to assess students in a fair manner -, and when students performed well and participated in the assessment. Teachers were also proud when they had developed a new assessment method and implemented it in their teaching community.

...at least in this group [of teachers] I am the one who gives most feedback to the students, such as personal feedback, which is without doubt one form of assessment.

\section{Negative Emotions}

Four negative emotions were observed: frustration, anxiety, shame and boredom. Frustration was identified from almost all interviews (14/16). This category also included the disappointment felt in situations where some positive anticipated outcome did not happen. The main entity that caused frustration were rules of assessment given by the university or the faculty. The teachers felt that the forced assessment methods were not always suitable for the learning objectives and testing the process of learning. Frustration was also felt when assessment was not rightful and equal to students. 
...then I got such a feeling that at least for one year the [university] organization should remain stable so that I could evaluate whether my developments [related to assessment] have been successful.

Furthermore, the closest teacher community caused frustration in relation to assessment. The teachers felt that the community did not discuss assessment, and that led to big differences between teachers and again endangered the rightfulness.

Time was also the subject of frustration. Assessment was considered too time-consuming, and the teachers felt they did not have time to assess as thoroughly as they thought would have been needed.

... when you have to assess the written task, it can happen quite routinely. If you have 70 students, you cannot analyze the answers, it is impossible within the working hours.

Some of the respondents were frustrated by the students, they felt that the students lacked motivation to learn but were mainly trying to pass the exams with minimal effort, or were not interested in the provided feedback.

...for some students the plain grade is enough and they do not even want to know what they can do or what they have learned, so sometimes it is frustrating to spend much time --- they should read the feedback but when the teacher has to give them a grade, so does anyone read it ever --- not all students are even interested in the feedback.

Seven teachers questioned their own abilities and motivation to assess the learning of the students in a proper way. 
.. now we have this style that teaching should be given in blocks, in very intensive periods, so I think that it makes formative assessment more difficult, because if you have very many students and a very short time, how do you have enough time to [assess]..

Boredom was only found four times, from three interviews. The reasons mentioned were monotonous assessment methods and heavy workload or pedagogical training that was felt to repeat the same contents from course to course relating to assessment.

It is sometimes boring when the same issues [related to assessment] are repeated over and over again in pedagogical training.

Assessment had induced anxiety in more than half of the interviewees. Almost always this emotion was focused on the teacher him/herself. The main trigger for anxiety was the fairness of the assessment: being objective especially if one knew the student, understanding the given answer correctly, having articulated the assessment criteria clearly enough and ignoring the actual learning process in the assessment, for example, if the student was a brilliant debater but not that good a writer. Teachers' anxiety was also triggered by thoughts concerning the students' demands of rightfulness and the possibility of misunderstandings when receiving the results. In five of the interviews, anxiety related to assessment could be interpreted as related to timing and workload. Therefore, some had lessened the number of assignments to be assessed.

I don't know... I think that frightening is a wrong word, neither stressful, but something where I need to be alert and sharp, and it is somehow more tiring than something else since also students have their pressures and emotions and they look very carefully at the given feedback, and especially rightfulness is very important.

Related to fairness some felt anxiety when discussing assessment practices with colleagues. Moreover, and related to students, teachers experienced these feelings if they feared that students would consider teachers' different requirements unfair. In addition, some mentioned that they were 
uncertain especially in the early stages of career development, but pedagogical development had eased it.

It is awfully hard to come up with meaningful criteria.

Often, there is always a slight fear of subjectivity, even though it is not said aloud...

Only five respondents expressed shame when they talked about assessment, usually related to fairness of assessment: when they admitted that they would not have had proper assessment grids or proper assessment criteria or that their way of assessment was too rough. The emotion of shame could also arise from not prioritizing assessment and feedback in teaching.

...I know I should - and I feel ashamed about it - organize feedback sessions...

The main triggers of each emotion type are listed in Table 2. We found four main sources of assessment-related emotions: situations where fairness of assessment is either fulfilled or at risk to fail; feelings of success in pedagogical development; divergent assessment methods, which help or hinder teaching or learning; and university or faculty's assessment culture, which may enhance or hinder teaching and learning.

[Table 2 about here]

\section{Discussion}

The aim of the current study was to investigate teachers' emotions related to assessment in higher education. Specifically, the study set out to investigate what kinds of emotions experienced university teachers associate to their work as an assessor and what triggers those emotions. We found the same categories of positive and negative emotions that correspond with Frenzel's (2014) and Pekrun's (2006) models. Positive emotions were less frequently observed in the interviews than negative ones, which was not in line with Postareff and Lindblom-Ylänne (2011) who identified more positive than negative emotions in teachers' interviews. However, five positive emotions 
(enjoyment, compassion, hope, relief and pride), and four negative emotions (frustration, anxiety, shame and boredom) were identified.

We observed one frequent positive emotion: enjoyment. It was present in almost all interviews. Feelings of enjoyment signal pleasure and satisfaction with something that is achieved, some upcoming event or being engaged in an enjoyable activity (Frenzel, 2014). Joy was especially related to certain assessment methods, such as oral and group examinationss and observing students. In previous studies, the main source of enjoyment has been the students' success (Frenzel 2014), and contact to students has been shown to strengthen teacher identity, inducing enjoyment and job satisfaction (van Lankveld et al. 2016).

Compassion was found in almost two thirds of the interviews. In terms of compassion, respondents showed concern for the students' welfare but also for society - how well qualified students are when entering working-life. Concern for students supports the earlier finding of Postareff and Lindblom-Ylänne (2011) that university teachers may have feelings of empathy and respect towards students.

Hope refers to thinking that desired future outcomes are likely to occur, and it influences goaldirected behaviors which affect goal achievement (Rand, Martin, and Shea 2011). In this data, teachers were hopeful that for instance development of assessment methods would decrease their workload. Relief was mostly present in collaboration with colleagues: sharing responsibility may ensure quality of teaching. This is in line with the finding that collegial and supportive work environments enhance teacher identity (van Lankveld et al. 2016). Pride is also a self-conscious emotion where the sense of personal responsibility is critical (I won because I practiced for hours). It is focused on specific behavior leading to success. (Oades-Sese, Matthews, and Lewis 2014.) Our respondents experienced pride after improving assessment methods, fairness of assessment or being able to take part in educational reform in their unit. 
Of the negative emotions frustration and anxiety were the most typical while shame and boredom were less common. Negative emotions are unpleasant, but they may increase effort to improve, such as frustration, or decrease effort, such as boredom (Pekrun et al. 2007). Frustration was observed from 14 interviews but boredom only from three. Frustration was typically related to rules of assessment given by the university, to colleagues or to students (they are not motivated). Van Lankveld et al. (2016) observed in their review that hierarchical work environments, where research was valued over teaching, were harmful for teacher identity development. It is thus logical that they can evoke feelings of frustration, too.

Anxiety was observed in over half of the interviews. In anxiety, the object was most often validity of assessment. For instance, teachers were anxious about their ability to be objective. Core of anxiety is perception of threat to ego or self-esteem, and not being able to cope with the threat (Smith and Lazarus, 1993). The frequency of anxiety in our observations indicates that it might be the emotion that is regularly associated with assessment also for experienced teachers. Shame is a self-consciousness emotion where the focus is on others' reactions. A person who feels shame is concerned with others' evaluation of her/his behavior. (Damasio 2003.) In teachers' talk about assessment, shame was present when they were concerned about students' reactions to their assessment practices. Boredom is opposite to engagement and harmful for learning (Mann and Robinson 2009), but there seems to be various strategies to cope with boredom in the context of education (Pekrun et al. 2010; Eren 2016). Boredom was mostly related to monotonous assessment methods, but also to pedagogical training that was felt to repeat the same topics from course to course.

We did not observe gratitude, hopelessness, sadness or anger, included in the TES (Frenzel 2014) or the CVT (Pekrun 2006). Gratitude, the emotional core of reciprocity (Devani and Shina 2012) has been found among students (Cownie 2017), but might not be essential for teachers, when related to assessment. Hope is associated to having agency and an ability to pursue goals (Snyder, Shorey, and 
Rand 2006). Low hope, or hopelessness, on the contrary, refers to low expectations to pursue goals. Although hopelessness is found in student samples, it may be rarer among experienced teachers due to their higher agency. Sadness and anger are so-called basic emotions (e.g. Nummenmaa et al. 2014), and anger is a salient emotions among teachers (Sutton \& Wheatley, 2003), but their absence from our data may be due to the organizational culture: different occupations (e.g. salesperson, flight attendants) may have different "feeling rules", which specify the range and intensity of emotions and which can be institutionalized by organizationally-sanctioned scripts. In Hochschild's (1979) terms, prescribing emotions is emotion work. It is plausible that sadness and anger do not belong to the role of experienced university teachers. The absence of anger in our data corresponds with Frenzel's (2014) notion that anger is a socially undesirable emotion in teaching contexts, and it may be reported less than it is felt.

We found several triggers for emotions; the main triggers were fairness of assessment, assessment methods, pedagogical development and assessment culture. Fairness of assessment (justice issues, validity and reliability of the assessment methods and criteria) evoked both positive (compassion, and pride) and negative emotions (frustration, anxiety and shame). This is logical considering that academics' emotions are most often studied under the topic of achievement emotions; emotions directly tied to achievement activities or achievement outcomes (Pekrun et al. 2007). Teachers have a responsibility to maintain validity of assessment that is critical to successful achievement activities and achievement outcomes. Fairness was the main trigger for anxiety and shame, which indicates its importance for teachers.

Related to the previous trigger, assessment methods evoked several positive emotions (joy, pride and compassion) and only one negative emotion (frustration). Teachers could feel concern for how different assessment methods affect students, insight about learning new ways to implement assessment or joy and pride by a successful assessment procedure. Frustration was related to for instance unsuitable or laborious assessment methods. This corresponds with Lackritz's (2004) 
results that workload issues, such as time used for grading and reading papers and assignments were related to emotional exhaustion of university teachers.

University/faculty assessment culture triggered positive emotions of joy and pride, and the negative emotion frustration. When the assessment culture gave freedom to choose assessment methods freely and supported learning, joy and pride were evoked, whereas a restrictive assessment culture caused frustration. This corresponds to van Lankveld et al.'s (2016) conclusion from their review that the woringk environment is an important factor for teachers' identity development.

From the most common triggers, pedagogical development was the only one that evoked merely positive emotions: joy and pride. Developing one's pedagogical skills could be enjoyable, and induce feelings of having achieved something important. This, again, is supported by van Lankveld et al.'s (2016) results that staff development activities were mostly found strengthening for teacher identity.

Our study has some limitations. It is exploratory with a small sample size and we interviewed only experienced teachers. However, we aimed to find as much variation as possible. Consequently, it would be important to study university teachers on different phases of their careers to get a picture of change in achievement emotions in academia. In addition, emotions were coded from the interviews abductively and they may be over interpreted. Sometimes emotions and their triggers were also mingled. For example, when the respondent was reporting that the assessment system is not fair to students and expressed frustration, the appraisal that triggered emotion was that students were not treated fairly, and this could also reflect compassion. We tried to avoid these problems by cross-coding and iterating the coding process several times, and by a reliability coding. Moreover, albeit there was a gender balance among the interviewees, all researchers are females. This may have unconsciously affected the coding and interpretations. The study was conducted in one cultural context, Finland. It is plausible that different cultures have different "feeling rules" (Hochschild 
1979), and results from some other culture would be different. There was also the problem of "lost in translation", when Finnish quotations were translated into English, and the quotations may have lost subtlety of meaning in this process.

\section{Conclusions}

In sum, our preliminary research indicates that assessment may evoke both positive and negative emotions, in line with previous studies. This study shows that fairness of assessment is a prominent issue in assessment. The results reflect teachers' role as judges and on the other hand facilitators of learning. Given that organizational culture has an impact on emotional expression (Hochschild 1979), as implications for future research, we may ask: Is there variation in experiencing emotions between novice and experienced higher education teachers? What regulates teachers' emotions in educational contexts? We argue that in order to help teachers to cope with negative emotions, pedagogical training should deal with emotions and their regulation in assessment. 


\section{References}

Beard, C., S. Clegg, and K. Smith. 2007. “Acknowledging Affective in Higher Education.” British Educational Research Journal 33 (2): 235-252.

Boyd, L. 2014. "Exploring the Utility of Workload Models in Academe: A Pilot Study." Journal of Higher Education Policy and Management 36 (3): 315-326.

Brown, L. D., T. T. Cai, and A. DasGupta. 2001. "Interval Estimation for a Binomial Proportion." Statistical Science 16 (2): 101-117.

Collins, M. E., and M. Amodeo. 2005. "Responding to Plagiarism in Schools of Social Work: Considerations and Recommendations." Journal of Social Work Education 41: 527-543.

Cowie, N. 2011. "Emotions that Experienced English as a Foreign Language (ELF) Teachers Feel about Their Students, Their Colleagues, and Their Work." Teaching and Teacher Education 27: $235-242$.

Cownie, F. 2017. “Gratitude and Its Drivers within Higher Education” Journal of Marketing for Higher Education 27 (2): 290-308. doi: 10.1080/08841241.2017.1389795

Damasio, A. 2003. Looking for Spinoza: Joy, Sorrow, and the Feeling Brain. Orlando: Harcourt.

Day, C., and R. Leitch. 2001. “Teachers' and Teacher Educations' Lives: The Role of Emotion.” Teaching and Teaching Education 17 (4): 403-415.

Dewani, P. P., and P.K. Sinha. 2012. "Gratitude: An Emotional Approach in Business Relationship Research.” Journal of Business Management 6 (1): 1-11. 
Eren, A. 2016. "Unidirectional Cycles of Boredom, Boredom Coping Strategies, and Engagement among Prospective Teachers." Social Psychology of Education 19: 895-924. doi: 10.1007/s1121801

Frenzel, A.C. 2014. “Teacher Emotions”. In International Handbook of Emotions in Education, edited by P. A. Alexander, R. Pekrun, and L. Linnenbrink-Garcia, 494-519. Routledge. Accessed on: 14 Jun 2018.

Frenzel, A. C., R., Pekrun, T., Goetz, L.M., Daniels, T.L., Durksen, B., Becker-Kurz, and R.M., Klassen. 2016. 'Measuring Teachers’ Enjoyment, Anger, and Anxiety: The Teacher Emotions Scales (TES)". Contemporary Educational Psychology 46: 148-163.

Gibbs, G., and C. Simpson. 2004. "Conditions under Which Assessment Supports Students' Learning." Learning and Teaching in Higher Education 5 (1): 2-31.

Hagenauer, G., and S. Volet. 2014. “'I Don’t Think I Could, You Know, Just Teach without Any Emotion': Exploring the Nature and Origin of University Teachers' Emotions." Research Papers in Education 29 (2): 240-262. doi: 10.1080/02671522.2012.754929

Hochschild, A. R. 1979. "Emotion Work, Feeling Rules, and Social Structure.” The American Journal of Sociology 85 (3): 551-575.

Ilott, I., and R. Murphy. 1997. "Feelings and Failing in Professional Training: The Assessors Dilemma." Assessment \& Evaluation in Higher Education 22 (3): 307-316.

Kyvik, S. 2013. “Academic Workload and Working Time: Retrospective Perceptions versus TimeSeries Data." Higher Education Quarterly 67 (1): 2-14. 
Lackritz, J. 2004. “Exploring Burnout among University Faculty: Incidence, Performance, and Demographic Issues.” Teaching and Teacher Education 20: 713-729.

van Lankveld, T., J. Schoonenboom, M. Volman, G. Croiset, and J. Beishuizen. 2016. “Developing a Teacher Identity in the University Context: A Systematic Review of the Literature." Higher Education Research \& Development 36 (2): 325-342. doi: 10.1080/07294360.2016.1208154.

Lutovac, S., R. Kaasila, J. Komulainen, and M. Maikkola. 2017. “University Lecturers’ Emotional Responses to and Coping with Student Feedback: A Finnish Case Study." European Journal of Psychology of Education 32 (2): 235-250. https://doi.org/10.1007/s10212-016-0301-1

Löfström, E., and A. Nevgi. 2014. "Giving Shape and Form to Emotion: Using Drawings to Identify Emotions in University Teaching." International Journal for Academic Development 19 (2): 99-111.

Mann, A., and A. Robinson. 2009. "Boredom in the Lecture Theatre: An Investigation into the Contributors, Moderators and Outcomes of Boredom amongst University Students.” British Educational Research Journal 35 (2): 243-258.

Melin, M., W. Astvik, and C. Bernhard-Oettel. 2014. "New Work Demands in Higher Education: A Study of the Relationship between Excessive Workload, Coping Strategies and Subsequent Health among Academic Staff.” Quality in Higher Education 20 (3): 290-308.

Moors, A., P.C. Ellsworth, K.R. Scherer, and N.H. Frijda. 2013. "Appraisal Theories of Emotion: State of the Art and Future Development." Emotion Review 5 (2): 119-124.

Nevgi, A., and E. Löfström. 2014. "Discourses on Student Plagiarism among University Teachers.” Paper presented at the EARLI SIG 4 \& SIG 17 Conference "Assessing transitions in learning", Leuven, August 20-22. 
Nummenmaa, L., E. Glerean, R. Hari, and J. K. Hietanen. 2014. "Bodily Maps of Emotions.” PNAS 111 (2): 646-651. https://doi.org/10.1073/pnas.1321664111.

Oades-Sese, G. V., T. A. Matthews, and M. Lewis. 2014. "Shame and Pride and Their Effects on Student Achievement." In International Handbook of Emotions in Education, edited by P. A. Alexander, R. Pekrun, and L. Linnenbrink-Garcia, 246-264. Routledge. Accessed on: 14 Jun 2018.

Ogbonna, E., and L. C. Harris. 2004. "Work Intensification and Emotional Labour among UK University Lecturers: An Exploratory Study.” Organization Studies 25 (7): 1185-1203. doi: $10.1177 / 0170840604046315$.

Pekrun, R. 2006. “The Control-Value Theory of Achievement Emotions: Assumptions, Corollaries, and Implications for Educational Research Practice." Educational Psychology Review 18: 315-341.

Pekrun, R., A. E. Elliot, and M. A. Maier. 2009. “Achievement Goals and Achievement Emotions: Testing a Model of Their Joint Relations with Academic Performance.” Journal of Educational Psychology 101 (1): 115-135.

Pekrun, R., A. C. Frenzel, T. Goetz, and R. P. Perry. 2007. “The Control-Value Theory of Achievement Emotions: An Integrative Approach to Emotions in Education.” In Emotion in education, edited by P. A. Schutz, and R. Pekrun, 13-36. San Diego, CA, US: Elsevier Academic Press.

Pekrun, R., T. Goetz, L.M. Daniels, R.H. Stupnisky, and R.P. Perry. 2010. "Boredom in achievement settings: Exploring control-value antecedents and performance outcomes of a neglected emotion.” Journal of Educational Psychology 102 (3): 531-549. 
Pekrun, R., T. Goetz, A.C. Frenzel, P. Barchfeld, and R.P. Perry. 2011. "Measuring Emotions in Students' Learning and Performance: The Achievement Emotions Questionnaire (AEQ). Contemporary Educational Psychology 36: 36-48.

Pekrun, R., S. Lichtenfed, R. March, K. Murayama, and T. Goetz. 2017. “Achievement Emotions and Academic Performance: Longitudinal Models of Reciprocal Effects." Child Development 88 (5): $1-18$.

Pekrun, R., and R. P. Perry. 2014. “Control-Value Theory of Achievement Emotions.” In International Handbook of Emotions in Education, edited by P.A. Alexander, R. Pekrun, and L. Linnenbrink-Garcia, 120-141. Routledge. Accessed on: 1 Nov 2018.

Peterson, E. R., G. T. L. Brown, and M. Jun. 2015. “Achievement Emotions in Higher Education: A Diary Study Exploring Emotions across an Assessment Event." Contemporary Educational Psychology 42: 82-96. http://dx.doi.org/10.1016/j.cedpsych.2015.05.002

Postareff, L., and S. Lindblom-Ylänne. 2011. "Emotions and Confidence within Teaching in Higher Education." Studies in Higher Education 36 (7): 799-813.

\section{http://doi.org/10.1080/03075079.2010.483279.}

Rand, K. L., A. D. Martin, and A. M. Shea. 2011. "Hope, but not Optimism, Predicts Academic Performance of Law Students beyond Previous Academic Achievement." Journal of Research in Personality 45 (6): 683-686.

Scouller, K. 1998. “The Influence of Assessment Method on Students' Learning Approaches: Multiple Choice Question Examination versus Assignment Essay.” Higher Education 35 (4): 453472.

Scouller, K., and M. Prosser. 1994. “Students' Experiences in Studying for Multiple Choice 
Question Examinations.” Studies in Higher Education 19 (3): 267-279.

Sergeant, ESG, 2018. “Epitools epidemiological calculators.” Ausvet Pty Ltd. Available at:

\section{http://epitools.ausvet.com.au}

Sherer, K.R. 2009. “The Dynamic Architecture of Emotion: Evidence for the Component Process Model”. Cognition \& Emotion 23(7): 1307-1351. DOI: 10.1080/02699930902928969

Smith, C.A. and R. S., Lazarus. 1993. "Appraisal Components, Core Relational Themes, and the Emotions”. Cognition \& Emotion 7 (3-4): 233-269. DOI:10.1080/02699939308409189

Snyder, C. R., H. S. Shorey, and K. L. Rand. 2006. "Using Hope Theory to Teach and Mentor Academically At-Risk Students." In Handbook of the Teaching of Psychology, edited by W. Buskist, and S. F. Davis, 170-174. Oxford: Blackwell.

Sutherland-Smith, W. 2005. "Pandora's Box: Academic Perceptions of Student Plagiarism in Writing." Journal of English for Academic Purposes 4: 83-95.

Sutton, R. E. 2007. “Teachers' Anger, Frustration, and Self-regulation.” In Emotion in Education, edited by P. S. Schutz, and R. Pekrun, 259-74. San Diego, CA: Academic Press.

Sutton, R. E., and K. F. Wheatley. 2003. 'Teachers' Emotions and Teaching: A Review of the Literature and Directions for Future Research.” Educational Psychology Review 15 (4): 327-358. http://doi.org/10.1023/A:1026131715856.

Timmermans, S., and I. Tavory. 2012. "Theory Construction in Qualitative Research: From Grounded Theory to Abductive Analysis." Sociological Theory 30(3): 167-186.

Watts, J., and N. Robertson. 2011. "Burnout in University Teaching Staff: A Systematic Literature Review." Educational Research 53 (1): 33-50. doi: 10.1080/00131881.2011.552235. 
Vehviläinen, S., E. Löfström, and A. Nevgi. 2017. "Dealing with Plagiarism in the Academic Community: Emotional Engagement and Moral Distress.” Higher Education 75 (1): 1-18.

Zembylas, M. 2003. "Emotions and Teacher Identity: Poststructural Perspective." Teachers and Teaching: Theory and Practice 9 (3): 213-238.

Table 1. The frequencies of emotions interpreted from the interviews $(N=16)$.

\begin{tabular}{|c|c|c|}
\hline Emotion & $\begin{array}{l}\text { Number (per cent; } 95 \% \text { confidence } \\
\text { interval) of times the emotions were } \\
\text { interpreted from the interviews }\end{array}$ & $\begin{array}{c}\text { Number of } \\
\text { academics } \\
\text { experiencing the } \\
\text { emotion }\end{array}$ \\
\hline Positive emotions & $104(36.4 ; 31.0-42.1)$ & \\
\hline Joy & 40 & 13 \\
\hline Compassion & 29 & 9 \\
\hline Hope & 15 & 8 \\
\hline Pride & 14 & 8 \\
\hline Relief & 6 & 5 \\
\hline Negative emotions & $182(63.6 ; 58.0-69.1)$ & \\
\hline Frustration/disappointment & 111 & 14 \\
\hline Uncertainty & 30 & 11 \\
\hline Anxiety & 27 & 10 \\
\hline
\end{tabular}




\begin{tabular}{|l|c|c|}
\hline Shame & 10 & 5 \\
\hline Boredom & 4 & 3 \\
\hline Altogether & $\mathbf{2 8 4}(\mathbf{1 0 0})$ & 16 \\
\hline
\end{tabular}

Table 2. Most common triggers evoking major emotions related to assessment.

\begin{tabular}{|l|l|l|l|l|}
\hline Trigger $\rightarrow$ & Farness of assessment & Pedagogical & Assessment methods & University/Faculty \\
Emotion $\downarrow$ & & development & assessment culture \\
\hline Positive & Compassion & Joy & Compassion & Joy \\
emotions & Joy & Pride & Joy & Pride \\
\hline Negative & Pride & Anxiety & Pride & \\
emotions & Frustration & & Frustration & Frustration \\
& Shame & & Shame & \\
\end{tabular}

Note: Emotions interpreted at least 10 times from the interviews were included. 